\title{
Dietary conjugated linoleic acids promote fatty streak formation in the C57BL/6 mouse atherosclerosis model
}

\author{
John S. Munday $^{1 *}$, Keith G. Thompson ${ }^{1}$ and Kerry A. C. James ${ }^{2}$ \\ ${ }^{1}$ Institute of Veterinary, Animal and Biomedical Sciences, Massey University, Palmerston North, New Zealand \\ ${ }^{2}$ New Zealand Institute for Crop and Food Research Limited, Palmerston North, New Zealand
}

(Received 8 June 1998 - Accepted 4 November 1998)

\begin{abstract}
Conjugated linoleic acids (CLA) are positional isomers of linoleic acid which have been suggested by some to possess antiatherosclerotic properties. To test this hypothesis, three groups of twenty C57BL/6 mice were fed on atherogenic diets containing: $5 \mathrm{~g} \mathrm{CLA} / \mathrm{kg}, 2 \cdot 5 \mathrm{~g} \mathrm{CLA}+2.5 \mathrm{~g}$ linoleic acid/kg or $5 \mathrm{~g}$ linoleic acid/ $\mathrm{kg}$. All diets were fed for 15 weeks and contained $(\mathrm{g} / \mathrm{kg})$ : triacylglycerol 145, free fatty acids 5, cholesterol 10 and cholic acid 5. At the completion of the experimental period, when data from both groups fed on CLA were combined, dietary CLA did not produce significant differences in body weight, serum total cholesterol concentration or serum HDL-cholesterol concentration. However, mice receiving CLA developed a significantly higher serum HDL-cholesterol : total cholesterol ratio and a significantly lower serum triacylglycerol concentration than controls. Despite causing a serum lipoprotein profile considered to be less atherogenic, the addition of CLA to the atherogenic diet increased the development of aortic fatty streaks. Considering the increased atherogenesis associated with dietary CLA in the present study, and the failure to demonstrate a significant beneficial effect of CLA in other animal studies, there is currently no conclusive evidence to support the hypothesis that CLA protect against atherogenesis.
\end{abstract}

Atherosclerosis: Conjugated linoleic acids: Dietary fat

Conjugated linoleic acids (CLA) are positional isomers of linoleic acid which have been shown to have anticarcinogenic properties (Parodi, 1997) and have been suggested to reduce atherogenesis (Haumann, 1996; Nicolosi et al. 1997). CLA are produced by bacteria and are found at highest concentrations in food products derived from ruminants (Haumann, 1996). Meat from ruminants contains approximately $5.5 \mathrm{mg}$ CLA/g fat while milk fat contains about $7 \mathrm{mg}$ CLA/g (Chin et al. 1992). Fats from vegetables and nonruminant animals contain a concentration of approximately $0.7 \mathrm{mg}$ CLA/g (Chin et al. 1992). Dietary supplements which contain CLA are also commercially available.

Two animal experiments investigating the effect of dietary CLA on atherosclerosis have been reported. In a study using hamsters, atherogenic diets containing CLA produced significantly smaller aortic fatty streaks (thought to be an early lesion of atherosclerosis; Fuster, 1994) than diets containing no free fatty acids (Nicolosi et al. 1997). However, no significant differences were observed when fatty streak formation in CLA-fed hamsters was compared with that in hamsters fed on diets containing linoleic acid (Nicolosi et al. 1997). Supplementation of cholesterol-fed rabbits with $0.5 \mathrm{~g} \mathrm{CLA} / \mathrm{d}$ did not significantly reduce fatty streak lesion development (Lee et al. 1994). Although it was initially thought that CLA may be able to protect LDL particles from oxidation (Ha et al. 1990; Ip et al. 1991; Lee et al. 1994; Nicolosi et al. 1997), a recent in vitro investigation (van den Berg et al. 1995) showed no antioxidant properties attributable to these fatty acids.

When fed on an atherogenic diet, C57BL/6 mice develop fatty streak lesions in the intima of the aortic sinus within 15 weeks. This enables trials involving relatively large numbers of animals without excessive cost, and, as these mice are inbred, they possess little genetic variation. Limitations of mice as a model for atherosclerosis development include the absence of lipoprotein(a) and cholesteryl ester transfer protein, both of which are known to influence human atherogenesis (Breslow et al. 1996).

The purpose of the present study was to investigate the effect of dietary CLA on early atherogenesis in C57BL/6 mice.

\section{Methods}

\section{Experimental animals}

Sixty, 6-week-old, female C57BL/6 mice were obtained from the Animal Breeding Station, Department of Laboratory 
Animal Sciences, University of Otago, New Zealand. Mice were housed in groups of five in solid-floored cages and kept in a room maintained at $22 \pm 1^{\circ}$, humidity $60 \pm 5 \%$, air exchange 12 times/h and on a $12 \mathrm{~h}$ light-dark cycle. The mice were acclimatized for 2 weeks, during which time they were fed on a commercial mouse diet. At the start of the trial the mean mouse weight was $20 \cdot 6 \mathrm{~g}$.

\section{Experimental design}

Twenty mice were randomly allocated into each of the three dietary groups. Two treatment groups received atherogenic diets containing either 5 or $2.5 \mathrm{~g} \mathrm{CLA} / \mathrm{kg}$. To ensure all diets contained equal amounts of free fatty acids, the diet containing $2.5 \mathrm{~g} \mathrm{CLA} / \mathrm{kg}$ also contained $2.5 \mathrm{~g}$ linoleic acid $/ \mathrm{kg}$. Mice in the control group were fed on a diet containing $5 \mathrm{~g}$ linoleic acid $/ \mathrm{kg}$.

The mice were fed ad libitum for 15 weeks. They were then fasted for between 8 and $12 \mathrm{~h}$, and killed by $\mathrm{CO}_{2}$ inhalation.

All procedures involving animals in this study were conducted under guidelines established by the Massey University Animal Ethics Committee and with their prior approval.

\section{Experimental diets}

The atherogenic diets used were similar to those reported by Nishina et al. (1990) and are illustrated in Table 1. All diets contained $(\mathrm{g} / \mathrm{kg})$ : triacylglycerol 145 , free fatty acids 5 , cholesterol 10 and cholic acid 5. The vitamin and mineral mixes were formulated according to guidelines established by the US National Research Council (1995). Solutions containing either $>95 \%$ CLA or $>99 \%$ linoleic acid were purchased from Nu-Chek-Prep Inc., Elysian, MN, USA. All other chemicals were purchased from either BDH Chemicals New Zealand Ltd, Palmerston North, New Zealand or Sigma Chemical Co., St Louis, MO, USA.

After the dry ingredients were mixed, water was added to form a dough which was then cut into strips and dried for $3 \mathrm{~d}$ at $29^{\circ}$. Once dry, the diets were stored in a freezer at $-20^{\circ}$. One week's supply of diet was removed from the freezer

Table 1. Composition of the experimental diets containing different levels of conjugated linoleic acids (CLA)

\begin{tabular}{lccc}
\hline Diet ... & Control & $2.5 \mathrm{~g} \mathrm{CLA} / \mathrm{kg}$ & $5 \mathrm{~g} \mathrm{CLA} / \mathrm{kg}$ \\
\hline Ingredients (g/kg as fed) & & & \\
Sucrose & $480 \cdot 64$ & $480 \cdot 64$ & $480 \cdot 64$ \\
Casein & 200 & 200 & 200 \\
Maize oil & 45 & 45 & 45 \\
Olive oil & 50 & 50 & 50 \\
Anhydrous milk fat & 50 & 50 & 50 \\
Cellulose & 50 & 50 & 50 \\
Salt mix & 50 & 50 & 50 \\
Vitamin mix & 50 & 50 & 50 \\
DL-Methionine & 3 & 3 & 3 \\
DL- $\alpha$-Tocopherol & $1 \cdot 36$ & $1 \cdot 36$ & $1 \cdot 36$ \\
CLA & 0 & $2 \cdot 5$ & 5 \\
Linoleic acid & 5 & $2 \cdot 5$ & 0 \\
Cholesterol & 10 & 10 & 10 \\
Cholic acid & 5 & 5 & 5 \\
\hline
\end{tabular}

${ }^{*}$ Formulated according to National Research Council (1995) guidelines. and kept refrigerated at $4^{\circ}$ until fed. Mice were given fresh diet from the refrigerator each day.

\section{Sample collection and processing}

Immediately after killing, between 0.5 and $1.0 \mathrm{ml}$ blood was collected from each mouse by cardiac puncture. The blood was transferred to a test tube and centrifuged at $1500 \mathrm{~g}$ for $15 \mathrm{~min}$ to separate serum. Serum cholesterol and triacylglycerol concentrations were determined using a Hitachi 704 autoanalyser (Boehringer Mannheim GmbH, Mannheim, Germany). Serum HDL-cholesterol concentrations were determined after selective precipitation of apolipoprotein B-containing lipoproteins using PEG 6000 (Izzo et al. 1981).

The liver from one mouse in each cage was fixed in neutral buffered formalin, embedded in paraffin, sectioned, and then stained with haematoxylin and eosin for routine histological examination.

\section{Morphological evaluation of fatty streaks}

The method used to quantify the aortic fatty streak lesions was based on that of Paigen et al. (1987b) and has been described in detail in a previous publication (Munday et al. 1998). Briefly, after formalin fixation, the hearts were passed through ascending concentrations of gelatin, frozen, and then sectioned using a cryostat. Once the aortic sinus was reached, twenty-four consecutive $10 \mu \mathrm{m}$ sections were taken and the cross-sectional area of fatty streak lesions in every second section was measured. All lesion assessment was performed blind by the same researcher.

\section{Statistical analysis}

Differences among dietary groups were investigated using ANOVA techniques. Relationships between serum lipids, body weight, and fatty streak formation were analysed using linear regression. All statistics were calculated using the Statistical Analysis Systems statistics package (SAS Institute Inc., Cary, NC, USA).

\section{Results}

A summary of the measurements made at the completion of the trial is presented in Table 2. During the trial, four mice were removed from each dietary group. In all instances, removal was due to weight loss resulting from the failure of mice to adapt to the experimental diet. Although accurate measurement of food intake is not practicable using this model, no differences in food disappearance rates were noticed and no significant differences in body weight were observed among the treatment groups.

No significant differences in mean serum total cholesterol concentration, or in mean serum HDL-cholesterol concentration, were observed among the dietary groups. Compared with controls, feeding $5 \mathrm{~g} \mathrm{CLA} / \mathrm{kg}$ diet significantly $(P=$ 0.008) increased the serum HDL-cholesterol : total cholesterol ratio. Although it approached significance $(P=0.09)$, the ratio observed in mice fed on $2.5 \mathrm{~g} \mathrm{CLA} / \mathrm{kg}$ diet was not significantly different from that of controls. When data from 
Table 2. Lipid variables in C57BL/6 mice fed on atherogenic diets containing different levels of conjugated linoleic acids (CLA) for 15 weeks*

(Mean values and standard deviations for sixteen mice per dietary group)

\begin{tabular}{|c|c|c|c|c|c|c|}
\hline \multirow[t]{2}{*}{ Diet ... } & \multicolumn{2}{|c|}{ Control } & \multicolumn{2}{|c|}{$2.5 \mathrm{~g} \mathrm{CLA} / \mathrm{kg}$} & \multicolumn{2}{|c|}{$5 \mathrm{~g} \mathrm{CLA} / \mathrm{kg}$} \\
\hline & Mean & SD & Mean & SD & Mean & SD \\
\hline Total aortic fatty streak area $\left(\mathrm{mm}^{2}\right)$ & $0 \cdot 13^{a}$ & 0.13 & $0.33^{b}$ & 0.27 & $0.25^{\mathrm{ab}}$ & 0.22 \\
\hline Serum total cholesterol $(\mathrm{mmol} / \mathrm{l})$ & $4 \cdot 17^{\mathrm{a}}$ & 0.74 & $3.57^{a}$ & 0.72 & $3.90^{\mathrm{a}}$ & $1 \cdot 16$ \\
\hline Serum HDL-cholesterol (mmol/l) & $1 \cdot 39^{a}$ & 0.21 & $1.40^{\mathrm{a}}$ & 0.34 & $1.61^{\mathrm{a}}$ & 0.31 \\
\hline HDL-cholesterol : total cholesterol & $0.34^{\mathrm{a}}$ & 0.08 & $0.40^{\mathrm{ab}}$ & 0.09 & $0.43^{b}$ & $0 \cdot 10$ \\
\hline Serum triacylglycerol $(\mathrm{mmol} / \mathrm{l})$ & $0.56^{\mathrm{a}}$ & 0.13 & $0.51^{\mathrm{ab}}$ & 0.08 & $0.47^{\mathrm{b}}$ & $0 \cdot 10$ \\
\hline Final body weight $(\mathrm{g})$ & $22 \cdot 01^{\mathrm{a}}$ & $1 \cdot 18$ & $21 \cdot 08^{a}$ & 1.22 & $21 \cdot 34^{\mathrm{a}}$ & 1.51 \\
\hline
\end{tabular}

${ }^{a, b}$ Mean values within a row not sharing a common superscript letter were significantly different, $P<0.05$.

${ }^{*}$ For details of diets and procedures, see Table 1 and p. 252.

both groups of CLA-fed mice were combined, dietary CLA significantly increased the HDL-cholesterol: total cholesterol ratio $(P=0 \cdot 01)$. Serum triacylglycerol concentrations were significantly higher in controls than in mice receiving $5 \mathrm{~g} \mathrm{CLA} / \mathrm{kg}$ diet $(P=0 \cdot 01)$, but not $2.5 \mathrm{~g} / \mathrm{kg}(P=0 \cdot 16)$. When data from the two CLA-fed groups were combined, the inclusion of CLA into the atherogenic diet significantly lowered serum triacylglycerol concentration $(P=0 \cdot 03)$.

Lipid-containing lesions were present in the intima of the aortic sinus in all mice. These lesions were most common close to the origins of the coronary arteries and at the base of the aortic valves and consisted of sub-endothelial collections of macrophages containing numerous lipid globules. In some mice, these globules were also found extracellularly around areas of macrophage accumulation and were present in the underlying media. Mice receiving diets containing $2.5 \mathrm{~g} \mathrm{CLA} / \mathrm{kg}(P=0.01)$, but not $5 \mathrm{~g} \mathrm{CLA} / \mathrm{kg}(P=0.12)$, developed a significantly greater area of fatty streaks than controls. When data from both groups of mice receiving CLA were combined, the addition of CLA to the diet significantly increased aortic fatty streak development $(P=$ $0 \cdot 02$ ). In the present study, fatty streak area was not correlated with the serum concentration of total cholesterol $(P=0 \cdot 5)$, HDL-cholesterol $(P=0 \cdot 4)$, or triacylglycerol $(P=$ $0 \cdot 3)$, or with either the HDL-cholesterol : total cholesterol ratio $(P=0 \cdot 9)$, or body weight $(P=0 \cdot 8)$.

All livers examined in this study were enlarged and pale tan in colour. Histological examination revealed diffuse hepatic lipidosis which did not differ in severity among groups on the basis of subjective assessment.

\section{Discussion}

In C57BL/6 mice, dietary CLA significantly increased aortic fatty streak formation. This is in contrast to a study by Lee $e t$ al. (1994) in which no significant differences in fatty streak development were observed between rabbits supplemented daily with either $0.5 \mathrm{~g}$ CLA or $0.5 \mathrm{~g}$ coconut oil. The results of the present study are also in contrast to a study using hamsters in which an atherogenic diet containing CLA resulted in significantly less atherogenesis than a control diet containing no free fatty acids. However, this result is difficult to interpret because control hamsters were also significantly heavier, raising the possibility that they may have consumed more of the atherogenic diet (Nicolosi et al.
1997). When CLA-fed hamsters were compared with hamsters fed on a control diet containing free linoleic acid, no differences in body weight or fatty streak formation were observed (Nicolosi et al. 1997).

In the present study, dietary CLA increased the serum HDL-cholesterol : total cholesterol ratio. As was observed in the study by Lee et al. (1994), this increase was produced by non-significant changes in both serum total cholesterol and HDL-cholesterol concentration. In hamsters, dietary CLA significantly lowered serum total cholesterol concentrations, however, HDL-cholesterol concentrations were unaltered by CLA in this model (Nicolosi et al. 1997). Hepatic lipid metabolism has been shown to be affected by CLA (Belury \& Kempa-Steczko, 1997) which may explain how they produce changes to the serum lipoprotein profile.

In human epidemiological studies and in previous experiments using the C57BL/6 mouse model, atherogenesis has been found to be inversely correlated with the serum HDLcholesterol: total cholesterol ratio (Paigen et al. 1987a; Luria et al. 1991; Stampfer et al. 1991; Nishina et al. 1993). In the present trial, lesion development was not correlated with this ratio or with any other variable measured. Therefore, CLA probably increased fatty streak formation by a mechanism independent of the serum lipoprotein profile, triacylglycerols or body weight.

It is possible that CLA promote atherogenesis by stimulation of the immune system. Interleukin-2 production (Wong et al. 1997), lymphocyte proliferation (Miller et al. 1994), and macrophage phagocytic activity (Cook et al. 1993) are all increased in cells cultured from animals supplemented with CLA. In C57BL/6 mice, foam cells are the predominant cell type within the fatty streaks (Stewart-Phillips \& Lough, 1991). Foam cells are produced when macrophages become engorged with lipid (Aviram, 1996) suggesting that promotion of the immune system, especially macrophage phagocytosis, could be expected to increase fatty streak formation. CLA may also promote atherogenesis by their ability to, depending on the concentration, both decrease and increase lipoprotein lipase (EC 3.1.1.34) activity (Park et al. 1997). Lipoprotein lipase has been suggested to be an important factor in determining early atherogenesis (Williams \& Tabas, 1995) so that alteration of enzyme activity may influence atherogenesis.

It is interesting to note that CLA did not promote atherogenesis in either the cholesterol-fed rabbit or hamster 
atherogenesis models (Lee et al. 1994; Nicolosi et al. 1997). This suggests that the mechanism by which CLA increase fatty streak development in C57BL/6 mice may be unique to this model. The most important question raised from this observation is whether or not CLA promote atherogenesis in man.

The addition of CLA to the diet resulted in a significant decrease in serum triacylglycerol concentration. This is in contrast to previous animal studies where no reduction in triacylglycerol concentrations were observed in rabbits supplemented with CLA (Lee et al. 1994) or when CLAfed hamsters were compared with hamsters fed on linoleic acid (Nicolosi et al. 1997).

When the two groups of mice fed on CLA are considered separately, only the group receiving $5 \mathrm{~g} \mathrm{CLA} / \mathrm{kg}$ diet developed an HDL-cholesterol : total cholesterol ratio and a serum triacylglycerol concentration significantly different from that in controls. The addition of $2.5 \mathrm{~g} \mathrm{CLA} / \mathrm{kg}$ to the atherogenic diet resulted in changes which approached, but did not attain statistical significance, suggesting that dietary CLA may have a dose-dependent effect on both these lipid variables. However, fatty streak development was significantly greater than in controls only in mice receiving diets containing $2.5 \mathrm{~g} \mathrm{CLA} /$ $\mathrm{kg}$. It is possible therefore, that dietary CLA at a level of both 5 and $2.5 \mathrm{~g} / \mathrm{kg}$ promoted atherogenesis, but that lesion formation was ameliorated in mice receiving $5 \mathrm{~g}$ CLA $/ \mathrm{kg}$ by the development of a less atherogenic serum lipoprotein profile.

No significant differences among the three dietary groups were observed in the mean mouse body weight. During preliminary studies, it was observed that diets containing either CLA or linoleic acid appeared to be less palatable than diets containing triacylglycerol. Free fatty acids have a 'soapy' taste and differences in feed intake (Park et al. 1997) and weight gain (Belury \& Kempa-Steczko, 1997; Nicolosi et al. 1997) were observed when animals fed on diets containing CLA were compared with those fed on diets containing triacylglycerol. Therefore, when using animals to investigate the physiological effects of CLA, it is essential that all the experimental diets contain equal quantities of free fatty acid. If this is not done, it becomes impossible to differentiate between the effects of CLA and the effects of differences in food intake.

In conclusion, the addition of CLA to an atherogenic diet fed to C57BL/6 mice resulted in the development of a serum lipoprotein profile considered to be less atherogenic. If human supplementation with CLA produces a less atherogenic lipoprotein profile without promoting atherogenesis, then CLA may be useful in preventing atherosclerotic disease. However, in the present study, dietary CLA increased the development of aortic fatty streaks and the possibility that dietary CLA also promote atherogenesis in human subjects requires further investigation. Considering the increased atherogenesis observed in this trial and the lack of significant atherosclerosis reduction seen in previous animal studies (Lee et al. 1994; Nicolosi et al. 1997), CLA cannot currently be regarded as antiatherogenic.

\section{Acknowledgements}

The authors wish to thank Sheryl Bayliss, Pat Davey, and Linley Fray for their excellent technical assistance.

\section{References}

Aviram M (1996) Interaction of oxidised low density lipoprotein with macrophages in atherosclerosis, and the antiatherogenicity of antioxidants. European Journal of Clinical Chemistry and Clinical Biochemistry 34, 599-608.

Belury MA \& Kempa-Steczko A (1997) Conjugated linoleic acid modulates hepatic lipid composition in mice. Lipids 32, 199-204.

Breslow J, Plump A \& Dammerman M (1996) New mouse models of lipoprotein disorders and atherosclerosis. In Atherosclerosis and Coronary Artery Disease, pp. 363-367 [V Fuster, R Ross and EP Topol, editors]. Philadelphia, PA: Lippincott-Raven Publishers.

Chin SF, Liu W, Storkson JM \& Pariza MW (1992) Dietary sources of conjugated dienoic isomers of linoleic acid, a newly recognised class of anticarcinogens. Journal of Food Composition and Analysis 5, 185-197.

Cook ME, Miller CC, Park Y \& Pariza M (1993) Immune modulation by altered nutrient metabolism: nutritional control of immuneinduced growth depression. Poultry Science 72, 1301-1305.

Fuster V (1994) Mechanisms leading to myocardial infarction: insights from studies of vascular biology (Lewis A. Conner Memorial Lecture). Circulation 90, 2126-2146.

Ha YL, Storkson JM \& Pariza MW (1990) Inhibition of benz(a)pyrene-induced mouse forestomach neoplasia by conjugated dienoic derivatives of linoleic acid. Cancer Research 50, 10971101.

Haumann BF (1996) Conjugated linoleic acid. International News on Fats, Oils and Related Materials 7, 152-159.

Ip C, Singh M, Thompson HJ \& Scimeca JA (1991) Mammary cancer prevention by conjugated dienoic derivative of linoleic acid. Cancer Research 51, 6118-6124.

Izzo C, Grillo F \& Murador E (1981) Improved method for determination of high-density-lipoprotein cholesterol I. Isolation of high-density lipoproteins by use of polyethylene glycol 6000 . Clinical Chemistry 27, 371-374.

Lee KN, Kritchevsky D \& Pariza MW (1994) Conjugated linoleic acid and atherosclerosis in rabbits. Atherosclerosis 108, 19-25.

Luria MH, Erel J, Sapoznikov D \& Gotsman MS (1991) Cardiovascular risk factor clustering and ratio of total cholesterol to high-density lipoprotein cholesterol in angiographically documented coronary artery disease. American Journal of Cardiology 67, 31-36.

Miller CC, Park Y, Pariza MW \& Cook ME (1994) Feeding conjugated linoleic acid to animals partially overcomes catabolic responses due to endotoxin injection. Biochemical and Biophysical Research Communications 198, 1107-1112.

Munday JS, Thompson KG, James KAC \& Manktelow BW (1998) Dietary antioxidants do not reduce fatty streak formation in the C57BL/6 mouse atherosclerosis model. Arteriosclerosis, Thrombosis, and Vascular Biology 18, 114-119.

National Research Council (1995) Nutrient Requirements of Laboratory Animals, 4th revised ed. Washington, DC: National Academy Press.

Nicolosi RJ, Rogers EJ, Kritchevsky D, Scimeca JA \& Huth PJ (1997) Dietary conjugated linoleic acid reduces plasma lipoproteins and early atherosclerosis in hypercholesterolemic hamsters. Artery 22, 266-277.

Nishina PM, Lowe S, Verstuyft J, Naggert JK, Kuypers FA \& Paigen B (1993) Effects of dietary fats from animal and plant sources on diet-induced fatty streak lesions in C57BL/6J mice. Journal of Lipid Research 34, 1413-1422.

Nishina PM, Verstuyft J \& Paigen B (1990) Synthetic low and high fat diets for the study of atherosclerosis in the mouse. Journal of Lipid Research 31, 859-869.

Paigen B, Holmes PA, Mitchell D \& Albee D (1987a) Comparison of atherosclerotic lesions and HDL-lipid levels in male, female, 
and testosterone-treated female mice from strains C56BL/6, $\mathrm{BALB} / \mathrm{C}$ and $\mathrm{C} 3 \mathrm{H}$. Atherosclerosis 64, 215-221.

Paigen B, Morrow A, Holmes P, Mitchell D \& Williams R (1987b) Quantitative assessment of atherosclerotic lesions in mice. Atherosclerosis 68, 231-240.

Park Y, Albright KJ, Liu W, Storkson JM, Cook ME \& Pariza MW (1997) Effect of conjugated linoleic acid on body composition in mice. Lipids 32, 853-858.

Parodi PW (1997) Cows' milk fat components as potential anticarcinogenic agents. Journal of Nutrition 127, 1055-1060.

Stampfer MJ, Sacks FM, Salvini S, Willett WC \& Henekens CH (1991) A prospective study of cholesterol, apolipoproteins and risk of myocardial infarction. New England Journal of Medicine 325, 373-381.
Stewart-Phillips JL \& Lough J (1991) Pathology of atherosclerosis in cholesterol-fed, susceptible mice. Atherosclerosis 90, 211218.

van den Berg JJM, Cook NE \& Tribble DL (1995) Reinvestigation of the antioxidant properties of conjugated linoleic acid. Lipids 30, 599-605.

Williams KJ \& Tabas I (1995) The response-to-retention hypothesis of early atherogenesis. Arteriosclerosis, Thrombosis, and Vascular Biology 15, 551-561.

Wong MW, Chew BP, Wong TS, Hosick HL, Boylston TD \& Shultz TD (1997) Effects of dietary conjugated linoleic acid on lymphocyte function and growth of mammary tumors in mice. Anticancer Research 17, 987-994. 


\section{Access full-text illind articles from the British Journal of $c \boldsymbol{a} b \boldsymbol{w} e \boldsymbol{b}$ Nutrition on the Internet}

\section{http://nutrition.cabweb.org}

The British Journal of Nutrition is now available on the Internet through Nutrition CABWeb, our new service providing desktop access to information in nutritional science.

Access controls are in place as of January 1999, and members of institutions/organizations with a current print subscription will be able to access the electronic version of the BJN for FREE once their institution/ organization has registered.

Visit the site now to find out more about the service and for details on how to register.

(10) $\mathrm{CABI}$ Publishing

CAB International

Wallingford

Oxon, OX10 8DE, UK

Tel: +44 (0)1491 832111

Fax: +44 (0)1491829198

Email: publishing@cabi.org
(10) CABI Publishing

CAB International

10 East 40th Street, Suite 3203

New York, NY 10016, USA

Tel: +1 2124817018

Fax: +12126867993

Email: cabi-nao@cabi.org 